\title{
Closing remarks from Calisia Conference sessions: (1) Family healthcare in Poland, Israel, Mozambique, and Ukraine, (2) COVID-19 pandemic, and (3) Human rights in time of armed conflicts
}

\author{
Andrzej Trybusz \\ Calisia University, Kalisz, Poland \\ ADDRESS FOR CORRESPONDENCE: Andrzej Trybusz, Calisia University, Nowy Świat 4, 62-800 Kalisz, Poland, \\ e-mail: andrzej.trybusz@gmail.com
}

\section{INTRODUCTION}

The sessions largely focused on issues of family life in times of crisis and armed conflicts, which were the main subjects of the Second World Conference on Family Health [1]. The following topics were explored during the three sessions: family health care in Poland, Israel, Mozambique and Ukraine; the COVID-19 pandemic; and human rights in times of armed conflict.

The presentations highlighted how crucial the discussed issues are to family health. They also made those attending aware of the influence of these issues on the functioning of the family, its development, stability and security.

\section{SESSION 1A: FAMILY HEALTHCARE IN POLAND, ISRAEL, MOZAMBIQUE, AND UKRAINE}

The discussion on family health care during session 1 showed how fundamentally its levels vary in different countries. This is due to many factors, which include, among others: the country's wealth, historical conditions, including the history of the health care system's development, the socio-political situation, and experience in the functioning of a medical care system. In addition to presenting a current assessment of the functioning of health care and indicating its shortcomings, an important element of the presentations was to define directions and methods of improvement so as to more effectively provide families with medical care.

Family health care in Poland faces limitations resulting from the weaknesses of the health care system. The main reason for this are the many years of under-financing, the lack of decisive measures to improve the provision of medical services, and staff shortages. This leads to extended waiting times for appointments, especially with a specialist or for scheduled diagnostics or surgery. Staffing problems and the ensuing consequences for the organization of work and the quality of patient care were discussed using the example of nurses and midwives. However, a similar situation is observed in other professional groups of medical workers. Hope for an improvement of the situation in the field of medical care is seen in, among other things, increasing expenditure on the health care system, as well as intensified education of medical staff (doctors, nurses, paramedics) by increasing the number of universities (faculties) educating medical personnel, as well as by increasing admission limits to existing universities.

A comprehensive approach to issues related to the care of pregnant women was presented using the example of the Western Galilee Medical Centre in Israel. Noteworthy aspects which were highlighted include the high level of antenatal care, safe delivery and further postnatal care. Women are provided with comfortable conditions of stay in the hospital, but also, most importantly, can expect a high degree of professionalism of the staff, full therapeutic protection and modern medical equipment. An important element at the pre- and postnatal stage is health education. The fact that Israel is a very diverse country in terms of ethnicity, religion and culture is also reflected in the diversity of patients treated at the Centre. Caring for them is very much tailored to the individual, taking these important (ethnic, religious, cultural) differences into account. The deeply humanistic and empathic approach to women in labour should be emphasized, which also takes into consideration the strengthening of family ties through, for example, the presence of the child's father during childbirth.

The situation in terms of caring for pregnant women is completely different in Mozambique. According to sta- 
tistics, an average of 17 women die every day in the country as a result of health complications during childbirth and puerperium (the 6-8-week period from the time of delivery of the placenta up to the resumption of normal ovulation), and annually there are 450 deaths reported per 100,000 live births. Bringing about such a high mortality are such factors as socio-economic conditions, limited access to medical care, and the poor quality of care, especially in small centres. The situation is worsened by the low social status of women (male dominance) and the related high levels of illiteracy and economic dependence of women. Most women with a higher level of education (secondary, or higher education) benefit from care in qualified urban centres, the rest have access mainly to rural centres where the level of care provided is quite low. In addition, in these small centres, women are often treated by medical staff in an uncultured manner, with a lack of privacy and confidentiality, or are given treatments without their consent. These problems are observed by the organizers of the health care system and actions are being taken to change this state of affairs. The goal set is to achieve by 2030 a perinatal mortality at a level of less than 70 deaths per 100,000 live births. The way to achieve this goal is to improve socio-economic indicators; better understanding of patients' cultural conditions and beliefs; elimination of inequalities in the social status of women; taking into account gender-related factors affecting women's health; and medical care tailored to the individual.

The health service in Ukraine is being reformed by building a modern model of basic medical care and specialist outpatient care. In basic medical care, the patient has the right to choose a physician, with the possibility of changing that choice where necessary. Specialist assistance is provided on the basis of referral from the primary care physician. Medical services are financed from the state budget through the National Health Service of Ukraine. An interesting solution is the motivational payroll system implemented in basic and specialized medical care, wherein an employee receives a basic (fixed) salary, according to a schedule and a variable part of the salary dependant on the quantity and quality of work.

\section{SESSION 2A: COVID-19 PANDEMIC}

Session 2 was devoted to the COVID-19 pandemic. The pandemic influenced the lives of every family in many areas. It has raised concern and anxiety about the health, and often the life of individuals and their families. Likewise, there is greater economic uncertainty related to the fear of losing one's job or bankruptcy of one's business, as well as the disruption of the education process at all levels due to often ineffective distance learning. Finally, the pandemic has given rise to the negative psychological effects resulting from the need to stay at home for long periods of time, and limited family and social contacts.

Apart from the above-mentioned problems caused by the pandemic, there also exist legal implications, a fact that was presented using the example of how Spanish family law is functioning during the COVID-19 pandemic. The law was characterised by the suspension of some civil rights, as well as court proceedings. In family law, alternating custody was maintained, and despite a lockdown being introduced, it was possible for parents to maintain contact with their child (one of the exceptions allowing people to leave the house). The pandemic situation is special in that the justice system is faced with problems that do not occur in normal times.

One of the most neglected aspects of the pandemic is mental health. Studies of this problem at the meta-analysis level carried out in many countries, as well as studies carried out at the University of Lodz, indicate the enormous scale of pathology for mental health caused by the pandemic. The high percentage of people diagnosed with various disorders, such as anxiety, depression, including suicidal thoughts, high levels of stress, and alcohol abuse, is particularly noteworthy and concerning. Bearing in mind the scale of mental disorders related to the COVID-19 pandemic on the one hand, and on the other the potential competences of psychiatry in the Polish health care system, one should expect that finding solutions to these problems will take a very long time.

One pre-condition for overcoming the pandemic is a significant increase in the percentage of people agreeing to be vaccinated. Currently, we are seeing a very considerable variation between countries, including within the EU, in terms of vaccination numbers. For example, in Portugal more than $80 \%$ of the population have been vaccinated, and in Bulgaria less than $20 \%$. There is also concern about the large variation in vaccination rates between continents, e.g. Europe - 53.55\% and Africa just $4.98 \%$. It has been scientifically proven beyond any doubt that the vaccines against COVID-19 are effective in protecting against the disease, especially against its severe course and death. In the absence of progress in vaccination, the SARS-CoV-2 virus will circulate in the unvaccinated population, creating successive mutations during replication that may eventually break down the immunity provided by the vaccines. Moreover, non-immunized people run the risk of contracting COVID-19, with the risk of serious complications, including death.

\section{SESSION 3A: HUMAN RIGHTS IN TIMES OF ARMED CONFLICTS}

Session 3 of the conference was devoted to human rights in times of armed conflicts. The international community has created a legal system striving to, among other, eliminate such conflicts. The legal acts adopted by the vast majority of countries in the world, especially the United Nations Charter, numerous treaties, resolutions and declarations, constitute sufficient regulations, which if complied with would allow for the elimination of armed conflicts in the world. This would require compliance with the principles on which the activities 
of the United Nations are based - promoting peace, development and human rights, and thus respect for the sovereign equality of states, the right of nations to self-determination, and prohibiting interference in the internal affairs of other states. Unfortunately, there are no effective mechanisms for enforcing the above principles. Analysis of reports by independent experts, e.g. on the waste of resources, various forms of discrimination and exclusion, economic exploitation of weak states, non-transparent politics and murky connections between international institutions do not give grounds for optimism that the conflicts plaguing the world will any time soon become a thing of the past.

We also have an extensive legal system that protects the rights and freedoms of individuals, as well as parties to armed conflicts. There are institutions established to supervise compliance with the adopted international regulations (for example the International Court of Justice, the European Court of Human Rights, the International Committee of the Red Cross). Nevertheless, we see no reduction in the number of human rights violations and bloody armed conflicts.

The presentation on the effects of genocide in Rwanda, which continue to this day, was extremely moving. This drama unfolded between April 6th and July 1994. During this time, some 800,000 to one million people were murdered in a fratricidal slaughter. This took place with passive attitude adopted by the UN, including its peacekeeping contingent - the UNAMIR, as well as the indifference of the world powers - the USA, France, the UK, Russia, and China. Particularly dramatic was the plight of children - orphans of genocide who lost their parents, often their siblings, and close and extended family members. This has translated into a significant number of mental illnesses among young people with a simultaneous lack of effective medical care. The people who experienced such a deep trauma entered adult life weighed down by negative emotions that were only exacerbated by the lack of a natural family environment.

The case of Albania during its communist dictatorship shows the degeneration in family life that a dictatorial regime can cause. The factory health service provided workers of a production plant, together with family members, comprehensive medical care at the highest level, including hospital care. The system invested in the health of those people useful for production purposes. The disabled and mentally ill were deprived of care. Families considered to be opponents of the system were imprisoned in concentration camps, where they were kept in inhumane conditions with no medical care, which often led to death, including that of children.

\section{CONCLUSIONS}

The program of the various sessions was thematically diverse, showing the impact on family health from various perspectives - the medical care system, the
COVID-19 pandemic, armed conflicts etc. A number of conclusions from the speeches indicate how much still needs to be done to ensure that families have the right conditions for a dignified life, a sense of security, and possibilities for the comprehensive development of family members. It is a truism to say that no conference can fix the world. But it is important to talk about difficult problems. They need to be publicized because that is one of the ways to reach those people who can effect such "repair measures". We need to proceed in accordance with the maxim "rocks can be hollowed out one drop after another".

\section{DISCLOSURE}

The author reports no conflict of interest.

\section{References}

1. Janik-Koncewicz K, Cicharska R. Report from the $2^{\text {nd }}$ World Calisia Conference on Family Health, Kalisz, Poland 24-25 October 2021. J Health Inequal 2021; 7(2): 78-84. 